\title{
Salinomycin inhibits canine mammary carcinoma in vitro by targeting cancer stem cells
}

\author{
HONGCHAO DU, BIN ZHOU, HONG ZHANG, YIPENG JIN, DI ZHANG and DEGUI LIN \\ Department of Veterinary Clinical Science, College of Veterinary Medicine, \\ China Agricultural University, Beijing 100193, P.R. China
}

Received March 24, 2016; Accepted February 17, 2017

DOI: $10.3892 / \mathrm{ol} .2017 .6164$

\begin{abstract}
Salinomycin (SAL), a polyether ionophore antibiotic, has been demonstrated to selectively kill cancer stem cells (CSCs) in various types of human tumor. The aim of the present study was to investigate the effects of SAL on canine mammary CSCs. CSCs in canine mammary carcinoma cell lines (CMT7364 and CIPp) were identified using a sphere formation assay and flow cytometry. The chemoresistance, invasive potential and expression of stem cell-associated proteins of these spheres was then analyzed. This demonstrated that the spheres exhibited characteristics of CSCs, including a cluster of differentiation (CD) $44^{+} / \mathrm{CD} 24^{-/ \text {low }}$ phenotype, upregulation of $\mathrm{Wnt} / \beta$-catenin signaling pathway-associated proteins and chemoresistance. The viability of the spheres was decreased in a concentration- and time-dependent manner following treatment with SAL, and the spheres did not exhibit increased resistance to SAL compared with their parental cells. In addition, exposure to SAL inhibited sphere-formation and invasive potential in canine mammary CSCs in a dose-dependent manner. Furthermore, SAL decreased the $\mathrm{CD} 44^{+} / \mathrm{CD} 24^{-/ \text {low }}$ population and downregulated the expression of $\mathrm{Wnt} / \beta$-catenin signaling-associated proteins $(\beta$-catenin, Cyclin D1 and octamer-binding transcription factor 4) in the spheres. In conclusion, the present study demonstrated that SAL is an effective inhibitor of canine mammary CSCs in vitro, indicating that SAL is a promising chemotherapeutic agent for the treatment of canine mammary carcinoma.
\end{abstract}

\section{Introduction}

Mammary gland tumors are the most common type of tumor in female dogs, and $\sim 50 \%$ of them are malignant $(1,2)$. Thus,

Correspondence to: Professor Degui Lin or Dr Di Zhang, Department of Veterinary Clinical Science, College of Veterinary Medicine, China Agricultural University, 2 Yuanminyuan Xilu, Beijing 100193, P.R. China

E-mail:csama@sina.com

E-mail: dzhangdvm@cau.edu.cn

Key words: salinomycin, cancer stem cells, spheres, canine mammary carcinoma it is a critical disease in veterinary clinical practice. However, following common cancer therapy (surgery, chemotherapy or radiotherapy, or their combinations), certain patients with canine mammary tumor still develop recurrence and/or metastases (2). As with humans, the presence of cancer stem cells (CSCs) within the tumor mass is a possible explanation for this clinical issue. CSCs are a small subset of cancer cells, which constitute a reservoir of self-sustaining cells with the exclusive ability to self-renew, thereby maintaining the tumor (3). CSCs are considered to be responsible for treatment resistance, recurrence and metastasis in various human cancers (4-6).

Increasing evidence supports the presence of CSCs in canine mammary tumors (7-10). Human breast CSCs are primarily characterized by cluster of differentiation (CD) $44^{+} / \mathrm{CD} 24^{-/ \text {low }}$ cells, sphere formation and active aldehyde dehydrogenase (11). These characteristics have also been observed in canine mammary CSCs; a CD $44^{+} / \mathrm{CD} 24^{-/ \text {low }}$ phenotype is also a specific maker of CSCs in canine mammary carcinoma $(8,9,12)$. Another feature of CSCs is overexpression of stem cell-associated genes, including octamer-binding transcription factor 4 (Oct-4) and sex determining region Y-box 2 (Sox-2) (10). Furthermore, activation of the Wnt/ $\beta$-catenin, Hedgehog and Notch signaling pathways confers resistance and survival to CSCs in human cancer (13). Similar to what has been observed in human cancer, canine mammary CSCs upregulate stem cell-associated genes (9) and activate the Wnt/ $\beta$-catenin signaling pathway (14). Canine mammary CSCs are highly tumorigenic, and exhibit multidrug resistance and invasive potential $(9,15)$; therefore, they serve an important role in the treatment resistance, recurrence and metastasis of canine mammary tumors.

Salinomycin (SAL), a polyether ionophore antibiotic isolated from Streptomyces albus, is widely used in farm animals as an anticoccidial drug (16). A previous review demonstrated that SAL is able to selectively deplete CSCs in different types of human cancer, including breast, gastric, hepatocellular, pancreatic, prostate and ovarian (13). SAL was also revealed to inhibit cell invasion and migration in a variety of cancer types (17). However, the mechanism of SAL anticancer activity in CSCs is not yet completely understood. A previous study demonstrated that SAL is a canonical Wnt/ $\beta$-catenin signaling pathway inhibitor, through effecting the expression of numerous Wnt-associated genes, including $\beta$-catenin, Cyclin D1, fibronectin, lymphoid enhancer-binding factor and 
low-density lipoprotein receptor-associated protein 6 (18). In addition, the $\mathrm{Wnt} / \beta$-catenin signaling pathway appears to be responsible for the antitumor effects of SAL on human breast cancer (19).

Based on the aforementioned data, new cytotoxic drugs that target canine CSCs, in addition to those in humans, are required. Therefore, the present study focused on whether SAL inhibits canine mammary CSCs. The effects of SAL on the viability, sphere-forming ability and invasive potential of cells derived from canine mammary carcinoma were analyzed. In addition, various proteins ( $\beta$-catenin, Cyclin D1 and Oct-4) and the $\mathrm{CD} 44^{+} / \mathrm{CD} 24^{-/ \text {low }}$ cell population were observed in response to SAL.

\section{Materials and methods}

Cell lines and cell culture. Canine mammary carcinoma CMT7364 cells (originally from mammary gland carcinoma, extracted during surgical resection at the Veterinary Teaching Hospital of China Agricultural University) and CIPp cells (20), [originally from mammary gland adenocarcinoma, a gift from the Laboratory of Veterinary Surgery (Graduate School of Agricultural and Life Sciences, University of Tokyo, Tokyo, Japan)] were grown in Dulbecco's modified Eagle's medium (DMEM) supplemented with $10 \%$ fetal bovine serum (FBS; both Gibco; Thermo Fisher Scientific, Inc., Waltham, MA, USA). All cells used in the present study were incubated at $37^{\circ} \mathrm{C}$ in an atmosphere containing $5 \% \mathrm{CO}_{2}$. Ethical approval for the present study was obtained from China Agricultural University (Beijing, China).

Chemicals and antibodies. SAL, doxorubicin (DOX) and cisplatin (DDP) were purchased from Sigma-Aldrich (Merck KGaA, Darmstadt, Germany). The antibodies used for western blot analysis were as follows: Primary antibodies, mouse anti- $\beta$-catenin (dilution, 1:1,000; cat. no. sc-133240); mouse anti- $\beta$-actin (dilution, 1:2,000; cat. no. sc-47,778); mouse anti-Oct-4 (dilution, 1:500; cat. no. sc-5279) and rabbit anti-Cyclin D1 (dilution, 1:1,000; cat. no. sc-753); secondary antibodies, goat anti-rabbit IgG-HRP (dilution, 1:2,000; cat. no. sc-2054) and goat anti-mouse IgG-HRP (dilution, 1:2,000; cat. no. sc-2005; all Santa Cruz Biotechnology, Inc., Dallas, TX, USA). Antibodies used in the flow cytometric assay were phycoerythrin anti-mouse CD24 (dilution, 1:200; cat. no. 553261) and allophycocyanin anti-mouse/human CD44 (dilution, 1:200; cat. no. 561859; both BD Biosciences, Franklin Lakes, NJ, USA).

Cell viability assay for chemoresistance. Cell spheres were obtained as previously described (9). CMT7364 and CIPp cells and their spheres were plated on 96 -well plates at a density of $3 \times 10^{3}$ cells/well. Cells were treated with a range of concentrations of DDP $(0-80 \mu \mathrm{M})$, DOX $(0-40 \mu \mathrm{M})$ and SAL $(0-20 \mu \mathrm{M})$ for 24, 48 and $72 \mathrm{~h}$. Cell viability was measured using the Cell Counting Kit-8 (CCK-8; Dojindo Molecular Technologies, Inc., Kumamoto, Japan) assay according to the manufacturer's protocol, then measuring the optical density (OD) with a microplate reader (ELx $808^{\mathrm{TM}}$; BioTek Instruments, Inc., Winooski, VT, USA) at $450 \mathrm{~nm}$. Cell viability was calculated according to the following formula: Cell viability $(\%)=[(\mathrm{OD}$ of test samples)-(OD of blank)]/[(OD of control samples)-(OD of blank)]x100. The half maximal inhibitory concentration $\left(\mathrm{IC}_{50}\right)$ was calculated with Prism software (version 6.01; GraphPad Software, Inc., La Jolla, CA, USA).

Sphere formation assay to identify CSCs. Cells were pretreated with $\operatorname{SAL}(0,3$ or $6 \mu \mathrm{M})$ for $48 \mathrm{~h}$. Cells were then harvested and plated at a density of $2 \times 10^{3}$ cells/well on an ultralow attachment 6-well plate (Corning Incorporated, Corning, NY, USA.) in serum-free DMEM/F12 medium (Gibco; Thermo Fisher Scientific, Inc.) supplemented with $10 \mathrm{ng} / \mathrm{ml}$ of basic fibroblast growth factor (PeproTech China, Suzhou, China), $10 \mathrm{ng} / \mathrm{ml}$ of epidermal growth factor (PeproTech China), $4 \mu \mathrm{g} / \mathrm{ml}$ of heparin (Sigma-Aldrich; Merck KGaA) and 50X B-27 (Gibco; Thermo Fisher Scientific, Inc.). The number of spheres was counted after a 7 -day incubation (at $37^{\circ} \mathrm{C}$ in atmosphere containing $5 \% \mathrm{CO}_{2}$ ) using an inverted phase-contrast microscope at $x 40$ magnification. Five fields of view from each plate were selected and counted, and the results were expressed as the total number of spheres.

Cell invasion assay. Tumor cell invasion capacity was analyzed using a Transwell chamber (cat. no. 3422; Corning Incorporated) according to the protocol of the manufacturer. In brief, the Transwell plate was coated with 25\% Matrigel (cat. no. 354248; BD Biosciences). DMEM containing 10\% FBS was added to the lower chamber, and $2 \times 10^{3}$ cells were seeded into the upper chamber with serum-free DMEM containing SAL $(0,3$ or $6 \mu \mathrm{M})$. The plate was incubated for $48 \mathrm{~h}$ at $37^{\circ} \mathrm{C}$, and the upper cells were then scraped off with a cotton swab. The cells on the lower side of the insert were fixed with $5 \%$ glutaraldehyde for $10 \mathrm{~min}$, followed by staining with $1 \%$ crystal violet in $2 \%$ ethanol for an additional $20 \mathrm{~min}$ at room temperature. The number of cells on the lower side of the filter were viewed under a microscope at x400 magnification. Five fields of view were randomly selected and cells were counted in each, with the results expressed as the mean number of cells/field.

Flow cytometry. Spheres treated with SAL $(0,3$ or $6 \mu \mathrm{M})$ for $48 \mathrm{~h}$ at $37^{\circ} \mathrm{C}$, and their parental cells which were not treated with SAL, were enzymatically dissociated with $0.25 \%$ Trypsin-EDTA (Gibco; Thermo Fisher Scientific, Inc.). Following washing with PBS plus $2 \%$ FBS, the cells were incubated with antibodies directed against CD44 and CD24 for $30 \mathrm{~min}$ at $4^{\circ} \mathrm{C}$ according to the manufacturer's protocol. The cell populations were then analyzed within $30 \mathrm{~min}$ by flow cytometry using a BD FACSCalibur flow cytometer (BD Biosciences), and data were analyzed with FlowJo (version 10.0.7; FlowJo, LLC, Ashland, OR, USA).

Western blot analysis. Spheres treated with SAL (0, 3 or $6 \mu \mathrm{M}$ ) for $48 \mathrm{~h}$ at $37^{\circ} \mathrm{C}$ and their parental cells were incubated with radioimmunoprecipitation assay buffer with phenylmethanesulfonyl fluoride. Equal amounts of protein $(30 \mu \mathrm{g})$ were resolved on a $10 \%$ gel using SDS-PAGE, then transferred to polyvinylidene fluoride (PVDF) membranes (Pall Life Sciences, Port Washington, NY, USA). The membrane was blocked with 5\% milk in PBS-Tween-20 at room temperature for $1 \mathrm{~h}$. The primary antibodies (anti- $\beta$-catenin, anti-Cyclin D1 
and anti-Oct-4) were then diluted in blocking buffer and added to individual PVDF membranes that were incubated at $4{ }^{\circ} \mathrm{C}$ overnight. The next day, the membranes were incubated with horseradish peroxidase-conjugated secondary antibodies for $2 \mathrm{~h}$ at room temperature and protein bands were detected with an enhanced chemiluminescence substrate (cat. no. 34080; Thermo Fisher Scientific, Inc.). $\beta$-actin was used as an internal control.

Statistical analysis. Statistical analyses were performed using GraphPad Prism software (version 6.01). Data are presented as the mean \pm standard deviation. A student's test was used when 2 groups were being compared, and a one-way analysis of variance when 3 groups were being compared. $\mathrm{P}<0.05$ was considered to indicate a statistically significant difference.

\section{Results}

CMT7364 and CIPp spheres exhibit characteristics of CSCs. CMT7364 and CIPp spheres (Fig. 1A) derived from parental cells, under anchorage-independent conditions and in the absence of FBS, exhibited characteristics of CSCs. Firstly, spheres exhibited a CD $44^{+} / \mathrm{CD} 24^{-/ \text {low }}$ phenotype and expressed an increased level of CD44 compared with their parental cells (Fig. 1B). In addition, western blot analysis demonstrated that stem cell marker Oct- 4 and the $\mathrm{Wnt} / \beta$-catenin-associated proteins $\beta$-catenin and cyclin D1 were overexpressed in spheres when compared with their parental cells (Fig. 1C). The $\mathrm{IC}_{50}$ was then calculated using a CCK- 8 assay. The results demonstrated that the $\mathrm{IC}_{50}$ of DDP and DOX were significantly increased in spheres compared with their parental cells $(\mathrm{P}<0.05$; Fig. 1D). These results indicate that the spheres derived from CMT7364 and CIPp cells are CSCs.

SAL inhibits the viability, sphere-forming ability and expression of stem cell-associated proteins of CMT7364 and CIPp spheres. The present study aimed to determine whether SAL targets canine mammary CSCs. The cytotoxic effect of SAL was evaluated using the CCK- 8 assay. The results demonstrated that SAL reduced cell viability in a time- and concentration-dependent manner $(\mathrm{P}<0.05$; Fig. 2A), and the $48 \mathrm{~h} \mathrm{IC}_{50}$ of SAL in spheres was similar compared with that of the parental cells (Fig. 2B). In addition, it was identified that SAL significantly inhibited canine mammary CSC sphere-formation, reducing the size and number of spheres $(\mathrm{P}<0.05$; Fig. 3A and $\mathrm{B})$. Western blot analysis revealed that the protein expression of $\beta$-catenin, Cyclin D1 and Oct- 4 in spheres was downregulated following treatment with SAL (Fig. 3C). To confirm that SAL targets canine mammary CSCs, the $\mathrm{CD} 44^{+} / \mathrm{CD} 24^{-/ \text {low }}$ phenotype of the spheres was measured following treatment with SAL. As illustrated in Fig. 3D, SAL reduced the proportion of $\mathrm{CD} 44^{+} / \mathrm{CD} 24^{-/ \text {low }}$ cells in the overall sphere population.

SAL inhibits the invasive potential of CMT7364 and CIPp spheres. Since CSCs have a high invasive potential, a Transwell assay was performed to evaluate the effect of SAL on the invasion of the spheres (Fig. 4). Compared with untreated cells, the number of cells that invaded the lower side of the Transwell chamber was significantly lower $(\mathrm{P}<0.05)$.

\section{Discussion}

Increasing evidence supports the CSC theory, which hypothesizes that CSCs are responsible for tumor growth, therapy resistance, recurrence and metastasis $(3,4,6,21,22)$. In canines, mammary CSCs are associated with a higher grade of carcinoma and poor prognosis $(7,8)$. In addition, canine mammary CSCs are typically resistant to common cancer therapies $(9,15)$. Therefore, it is important to identify novel drugs targeting CSCs for the eradication of canine, and human, mammary tumors. A previous review has demonstrated that SAL selectively depletes CSCs in different types of human cancer, likely by interfering with ATP-binding cassette drug transporters, the Wnt/ $\beta$-catenin signaling pathway and other CSC-associated signaling pathways (13). Thus, the present study investigated whether SAL inhibits CSCs in canine mammary tumors.

The sphere formation assay is a useful tool to identify CSCs. Previous studies have used this method to analyze the sphere-forming ability of canine mammary CSCs $(15,23)$. This method has also been used to investigate novel therapeutic drugs in humans and canines $(14,24)$. In the present study, it was observed that spheres from canine mammary carcinoma cell lines overexpressed the stem cell markers CD44 and Oct-4, and exhibited chemoresistance to DOX and DDP. These findings indicate that the spheres derived from CMT7364 and CIPp are CSCs.

Spheres may form single suspended cells under serum-free conditions, which is important for the self-renewal capacity of CSCs (9). The present study demonstrated that SAL reduced cell viability in a time- and concentration-dependent manner, and also inhibited sphere formation by reducing the number and size of spheres. In addition, the $\mathrm{IC}_{50}$ of SAL in spheres and their parental cells were similar, which indicates that canine mammary CSCs are not resistant to SAL. A CD $44^{+} / \mathrm{CD} 24^{-/ \text {low }}$ phenotype is a specific maker of CSCs in canine mammary carcinoma (8). In the present study, SAL treatment reduced the $\mathrm{CD} 44^{+} / \mathrm{CD} 24^{-/ \text {low }}$ cell population. A previous study identified that Oct- 4 is as an adequate marker of CSCs of canine mammary tumors (25), and overexpression of Oct-4 has been associated with malignancy and poor outcomes (26). Thus, the level of expression change of Oct-4 after drug treatment may be used to evaluate the ability to specifically target CSCs. In the present study, the expression of Oct-4 protein was decreased in spheres following treatment with SAL. These findings suggest that SAL inhibits CSCs in canine mammary tumors.

The canonical Wnt/ $\beta$-catenin signaling pathway serves an essential role in cell proliferation and migration, and in the self-renewal of CSCs (27). A previous study has identified that this signaling pathway is upregulated in human breast CSCs (28). Similar to in humans, the present study revealed that stem cell-like spheres overexpressed the Wnt/ $\beta$-catenin signaling pathway-associated proteins $\beta$-catenin and Cyclin D1, indicating that this signaling pathway is also upregulated in canine mammary CSCs. Previous studies have demonstrated that SAL targets CSCs in various tumors, including gastric cancer, osteosarcoma and lung cancer, by impacting the Wnt/ $\beta$-catenin signaling pathway (29-31). Notably, in the present study the protein level of $\beta$-catenin and Cyclin D1 in spheres was decreased following treatment with 
A

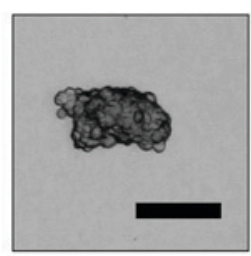

CMT7364

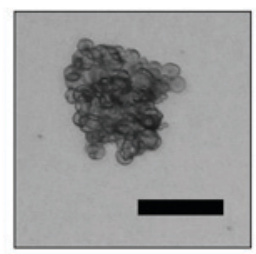

$\mathrm{CIPp}$
C

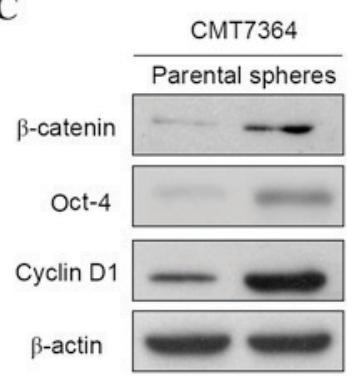

B
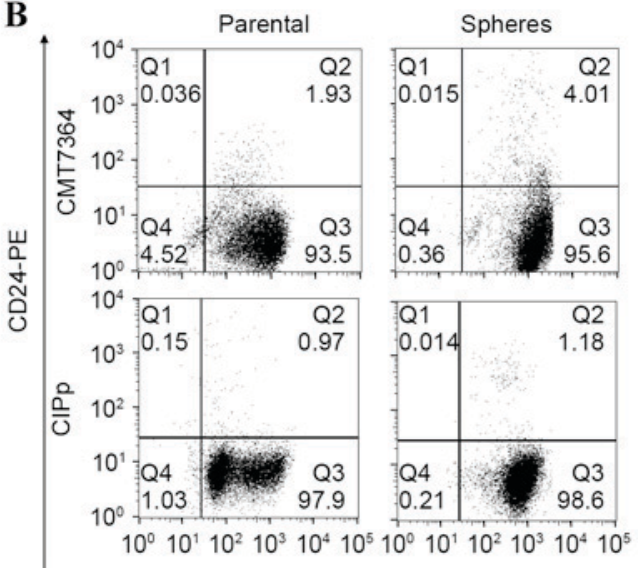

CD44-APC

D
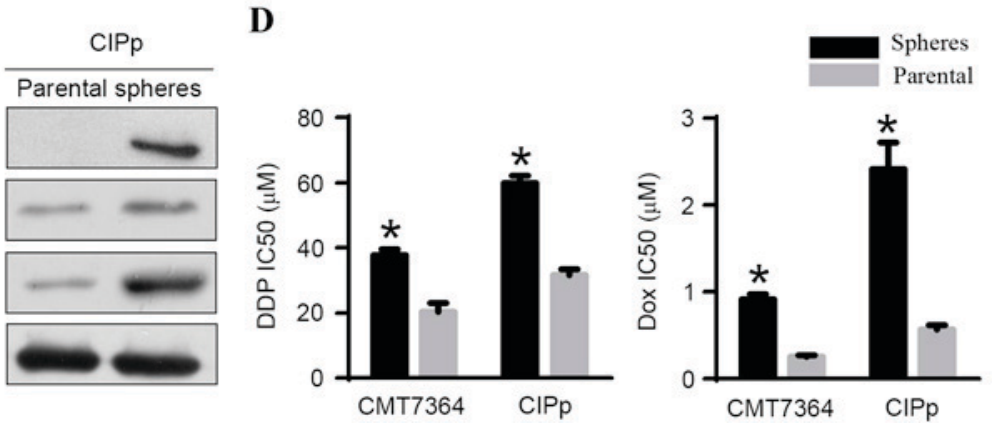

Figure 1. Canine mammary cancer stem cells were identified using a sphere-formation assay and flow cytometry, and their expression of Wnt/ $\beta$-catenin signaling pathway-associated proteins and chemoresistance analyzed. (A) Representative morphology of spheres derived from the canine mammary carcinoma cell lines CMT7364 and CIPp (scale bar, $100 \mu \mathrm{M}$ ). (B) Flow cytometric analysis of the expression of CD44 and CD24 in spheres and their parental cells. The cells in Q3 correspond to CD $44^{+} / \mathrm{CD} 24^{-/ \mathrm{low}}$ cells. Results are demonstrated as representative images of three independent experiments. (C) Protein levels of $\beta$-catenin, Oct-4 and Cyclin D1 in spheres and their parental cells, measured by western blot analysis. These proteins were overexpressed in spheres compared with their parental cells. (D) The $48 \mathrm{~h} \mathrm{IC}_{50}$ of DDP and DOX in spheres and their parental cells. Results are presented as the mean \pm standard deviation ( $\mathrm{n}=3$ ). ${ }^{*} \mathrm{P}<0.05$ vs. the parental cells. $\mathrm{IC}_{50}$, half maximal inhibitory concentration; CD, cluster of differentiation; PE, phycoerythrin; APC, allophycocyanin; Oct-4, octamer-binding transcription factor 4; Q, quadrant; DDP, cisplatin; DOX, doxorubicin.

A

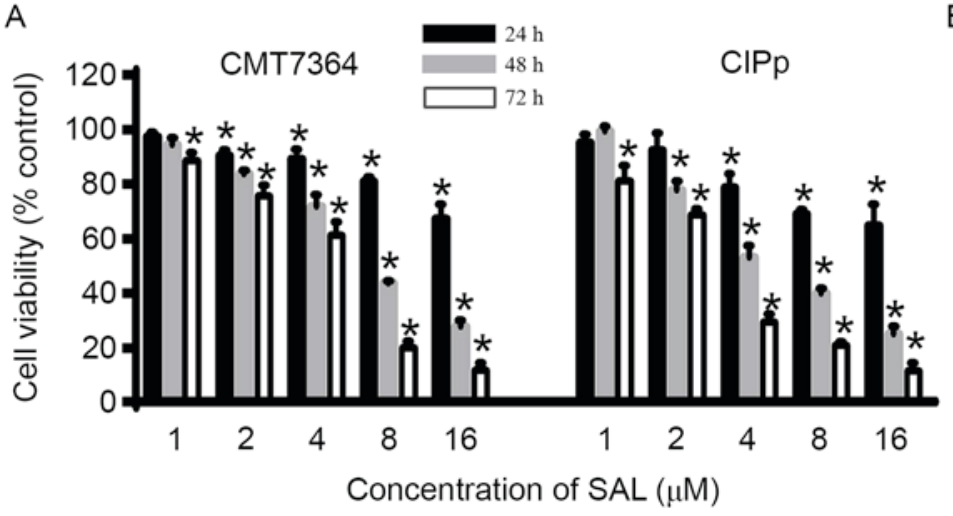

B

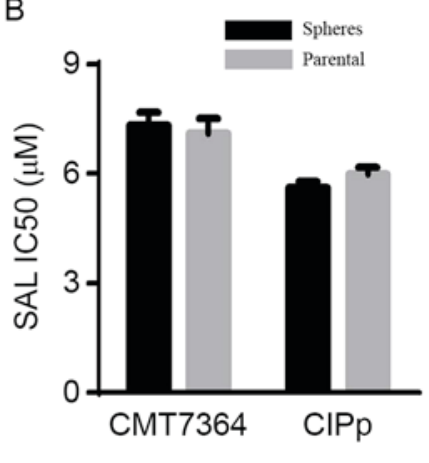

Figure 2. Cytotoxic effect of SAL on canine mammary cancer stem cells. (A) Cells were exposed to SAL for 24,48 or 72 h, and cell viability was assessed using the Cell Counting Kit- 8 assay. ${ }^{*} \mathrm{P}<0.05$ vs. the control group. (B) The $48 \mathrm{~h} \mathrm{IC} \mathrm{I}_{50}$ of SAL in spheres and their parental cells. Results are presented as the mean \pm standard deviation $(\mathrm{n}=3)$. SAL, salinomycin; $\mathrm{IC}_{50}$, half maximal inhibitory concentration.

SAL. This suggests that the Wnt/ $/$-catenin signaling pathway is associated with the effect of SAL on canine mammary CSCs.

Tumor metastasis is a major cause of mortality in humans and canines with cancer. CSCs possess migration and invasion potential, driving metastatic tumor formation $(21,22)$. However, there are few effective treatments for patients with metastatic disease.
Recently, studies have indicated that SAL inhibits cell migration and invasion in a variety of cancer types in vitro (17), in addition to reducing metastasis in vivo $(32,33)$. In the present study, the invasive ability of canine mammary CSCs was decreased following treatment with SAL in vitro; however, whether SAL has inhibits the metastasis of canine mammary tumor cells requires additional study. 


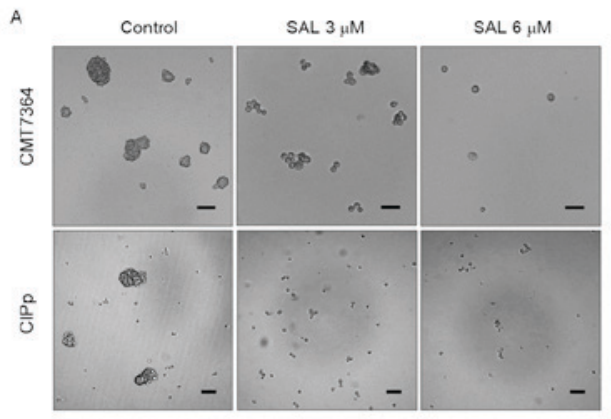

B
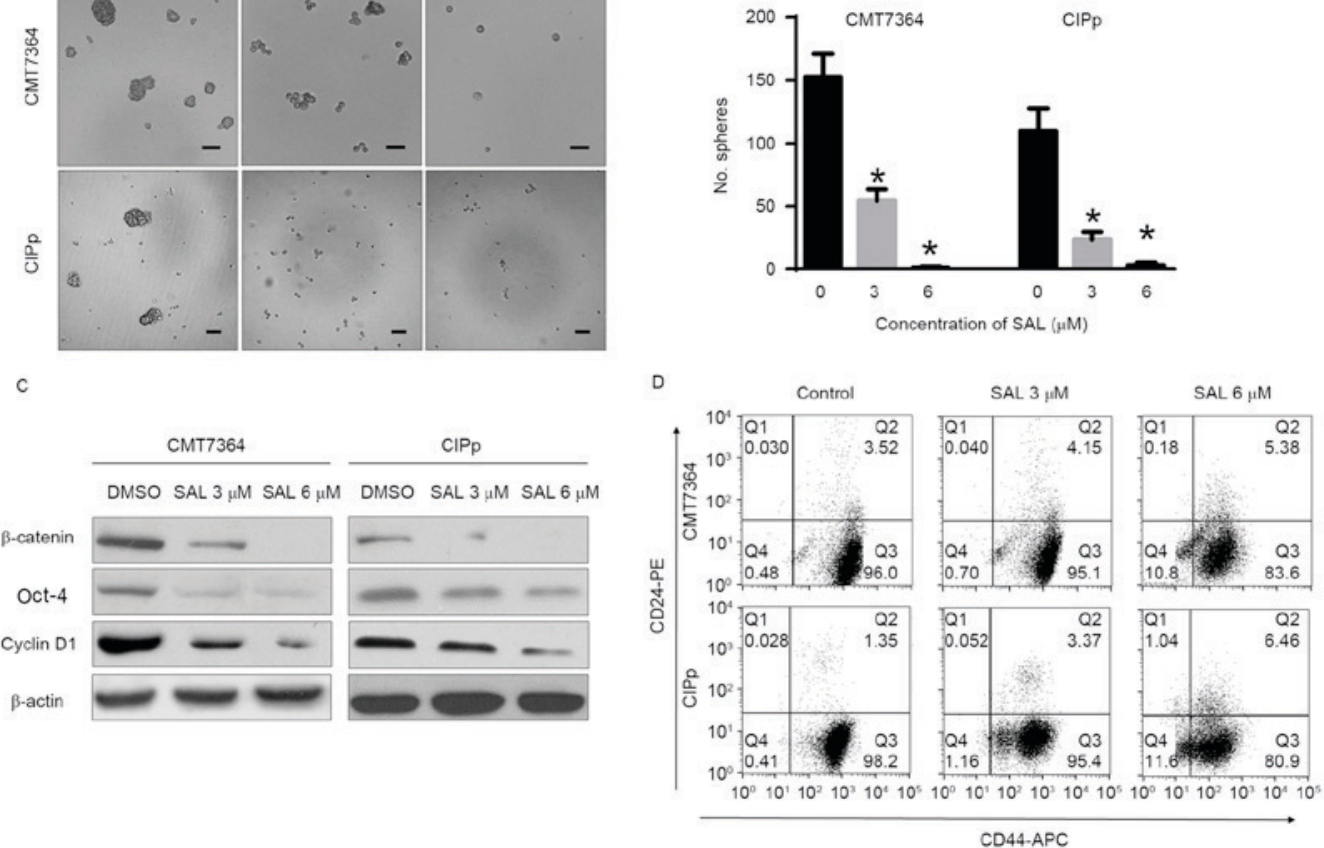

Figure 3. SAL inhibits canine mammary cancer stem cells in vitro. (A) Representative morphology of spheres derived from CMT7364 and CIPp cells that were pretreated with SAL for $48 \mathrm{~h}$ (scale bar, $100 \mu \mathrm{M}$ ). The size of SAL-treated spheres was smaller. (B) The number of spheres was reduced following treatment with SAL. "P $<0.05$ vs. the control group. (C) Western blot analysis demonstrated decreased $\beta$-catenin, Oct- 4 and Cyclin D1 expression in the spheres following treatment with SAL for $48 \mathrm{~h}$. (D) The percentage of CD44 $/ \mathrm{CD} 24^{- \text {llow }}$ spheres following treatment with SAL $48 \mathrm{~h}$ was reduced. Results are demonstrated as representative images of three independent experiments. SAL, salinomycin; DMSO, dimethyl sulfoxide; Oct-4, octamer-binding transcription factor 4; CD, cluster of differentiation; PE, phycoerythrin; APC, allophycocyanin; Q, quadrant.
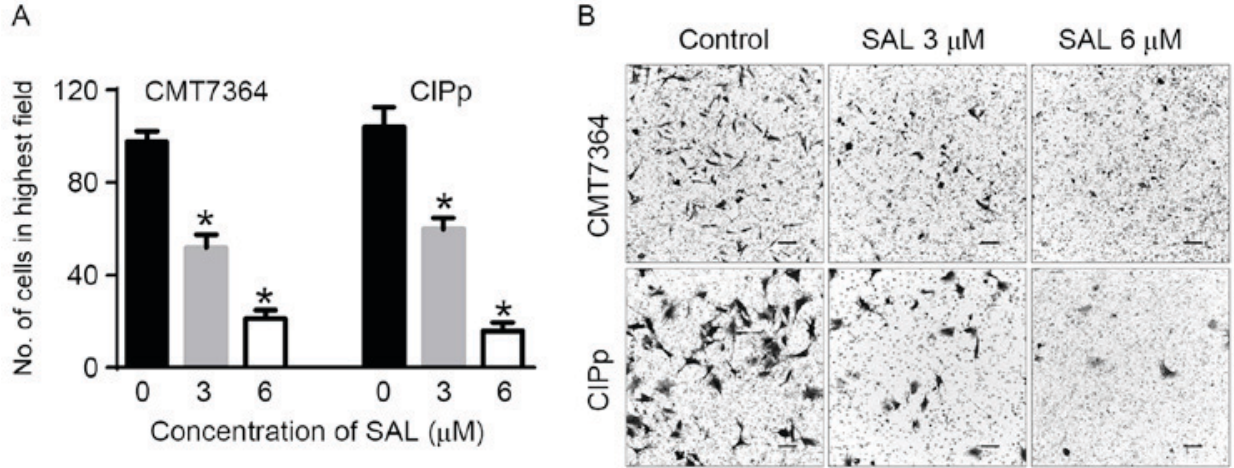

Figure 4. SAL inhibits the invasive ability of canine mammary cancer stem cells. (A) The number of invading cells were reduced following treatment with SAL in a Transwell invasion assay. Results are presented as the mean \pm standard deviation ( $n=5$ ). $P<0.05$ vs. the control group. (B) Representative micrographs of migrated cells following treatment with SAL (scale bar, $100 \mu \mathrm{M}$ ).

In conclusion, the present study identified that SAL is an effective inhibitor of canine mammary CSCs in vitro, indicating that SAL is a promising chemotherapeutic for the treatment of canine mammary carcinoma.

\section{Acknowledgements}

The authors thank the Laboratory of Veterinary Surgery of the Graduate School of Agricultural and Life Sciences at the University of Tokyo, for their gift of the canine mammary carcinoma cell line CIPp. The present study was supported by the National Natural Science Foundation of China (grant no. 31372489).

\section{References}

1. Vail DM and MacEwen EG: Spontaneously occurring tumors of companion animals as models for human cancer. Cancer Invest 18: 781-792, 2000.

2. Sleeckx N, De Rooster H, Veldhuis Kroeze EJ, Van Ginneken C and Van Brantegem L: Canine mammary tumours, an overview. Reprod Domest Anim 46: 1112-1131, 2011.

3. Clarke MF, Dick JE, Dirks PB, Eaves CJ, Jamieson CH, Jones DL, Visvader J, Weissman IL and Wahl GM: Cancer Stem cells-perspectives on current status and future directions: AACR workshop on cancer stem cells. Cancer Res 66: 9339-9344, 2006.

4. Visvader JE and Lindeman GJ: Cancer stem cells in solid tumours: Accumulating evidence and unresolved questions. Nat Rev Cancer 8: 755-768, 2008.

5. Hu Y and Fu L: Targeting cancer stem cells: A new therapy to cure cancer patients. Am J Cancer Res 2: 340-356, 2012. 
6. Mitra A, Mishra L and Li S: EMT, CTCs and CSCs in tumor relapse and drug-resistance. Oncotarget 6: 10697-11711, 2015.

7. Im KS, Jang YG, Shin JI, Kim NH, Lim HY, Lee SM, Kim JH and Sur JH: CD44+/CD24- cancer stem cells are associated with higher grade of canine mammary carcinomas. Vet Pathol 52: 1041-1044, 2015.

8. Magalhães GM, Terra EM, de Oliveira Vasconcelos R, de Barros Bandarra M, Moreira PR, Rosolem MC and Alessi AC: Immunodetection of cells with a CD44+/CD24- phenotype in canine mammary neoplasms. BMC Vet Res 9: 205,2013.

9. Michishita M, Akiyoshi R, Yoshimura H, Katsumoto T, Ichikawa H, Ohkusu-Tsukada K, Nakagawa T, Sasaki N and Takahashi K: Characterization of spheres derived from canine mammary gland adenocarcinoma cell lines. Res Vet Sci 91: 254-260, 2011

10. Leis O, Eguiara A, Lopez-Arribillaga E, Alberdi MJ, Hernandez-Garcia S, Elorriaga K, Pandiella A, Rezola R and Martin AG: Sox 2 expression in breast tumours and activation in breast cancer stem cells. Oncogene 31: 1354-1365, 2012.

11. Oliveira LR, Jeffrey SS and Ribeiro-Silva A: Stem cells in human breast cancer. Histol Histopathol 25: 371-385, 2010.

12. Michishita M, Akiyoshi R, Suemizu H, Nakagawa T, Sasaki N, Takemitsu H, Arai T and Takahashi K: Aldehyde dehydrogenase activity in cancer stem cells from canine mammary carcinoma cell lines. Vet J 193: 508-513, 2012.

13. Naujokat $\mathrm{C}$ and Steinhart R: Salinomycin as a drug for targeting human cancer stem cells. J Biomed Biotechnol 2012: 950658, 2012.

14. Torres CG, Olivares A and Stoore C: Simvastatin exhibits antiproliferative effects on spheres derived from canine mammary carcinoma cells. Oncol Rep 33: 2235-2244, 2015.

15. Pang LY, Cervantes-Arias A, Else RW and Argyle DJ: Canine mammary cancer stem cells are radio- and chemo- resistant and exhibit an epithelial-mesenchymal transition phenotype. Cancers (Basel) 3: 1744-1762, 2011

16. Zhou S, Wang F, Wong ET, Fonkem E, Hsieh TC, Wu JM and Wu E: Salinomycin: A novel anti-cancer agent with known anti-coccidial activities. Curr Med Chem 20: 4095-4101, 2013.

17. Kopp F, Hermawan A, Oak PS, Herrmann A, Wagner E and Roidl A: Salinomycin treatment reduces metastatic tumor burden by hampering cancer cell migration. Mol Cancer 13: 16, 2014.

18. Lu D, Choi MY, Yu J, Castro JE, Kipps TJ and Carson DA: Salinomycin inhibits Wnt signaling and selectively induces apoptosis in chronic lymphocytic leukemia cells. Proc Natl Acad Sci USA 108: 13253-13257, 2011.

19. Lu W and Li Y: Salinomycin suppresses LRP6 expression and inhibits both Wnt/ $\beta$-catenin and mTORC1 signaling in breast and prostate cancer cells. J Cell Biochem 115: 1799-1807, 2014.
20. Uyama R, Nakagawa T, Hong SH, Mochizuki M, Nishimura R and Sasaki N: Establishment of four pairs of canine mammary tumour cell lines derived from primary and metastatic origin and their E-cadherin expression. Vet Comp Oncol 4: 104-113, 2006.

21. Dalerba P and Clarke MF: Cancer stem cells and tumor metastasis: First steps into uncharted territory. Cell Stem Cell 1: 241-242, 2007

22. Li F, Tiede B, Massagué J and Kang Y: Beyond tumorigenesis: Cancer stem cells in metastasis. Cell Res 17: 3-14, 2007.

23. Grange C, Lanzardo S, Cavallo F, Camussi G and Bussolati B: Sca-1 identifies the tumor-initiating cells in mammary tumors of BALB-neuT transgenic mice. Neoplasia 10: 1433-1443, 2008.

24. Simmons MJ, Serra R, Hermance N and Kelliher MA: NOTCH1 inhibition in vivo results in mammary tumor regression and reduced mammary tumorsphere-forming activity in vitro. Breast Cancer Res 14: R126, 2012.

25. Ferletta M, Grawé J and Hellmén E: Canine mammary tumors contain cancer stem-like cells and form spheroids with an embryonic stem cell signature. Int J Dev Biol 55: 791-799, 2011.

26. Huang J, Zhang D, Xie F and Lin D: The potential role of COX-2 in cancer stem cell-mediated canine mammary tumor initiation: An immunohistochemical study. J Vet Sci 16: 225-231, 2015.

27. Curtin JC and Lorenzi MV: Drug discovery approaches to target Wnt signaling in cancer stem cells. Oncotarget 1: 552-566, 2010

28. Zhao Z, Lu P, Zhang H, Xu H, Gao N, Li M and Liu C: Nestin positively regulates the $\mathrm{Wnt} / \beta$-catenin pathway and the proliferation, survival and invasiveness of breast cancer stem cells. Breast Cancer Res 16: 408, 2014.

29. Tang QL, Zhao ZQ, Li JC, Liang Y, Yin JQ, Zou CY, Xie XB, Zeng YX, Shen JN, Kang T and Wang J: Salinomycin inhibits osteosarcoma by targeting its tumor stem cells. Cancer Lett 311: 113-121, 2011.

30. Mao J, Fan S, Ma W, Fan P, Wang B, Zhang J, Wang H, Tang B, Zhang Q, Yu X, et al: Roles of Wnt/ $\beta$-catenin signaling in the gastric cancer stem cells proliferation and salinomycin treatment. Cell Death Dis 5: e1039, 2014.

31. Zhang X, Lou Y, Zheng X, Wang H, Sun J, Dong Q and Han B: Wnt blockers inhibit the proliferation of lung cancer stem cells. Drug Des Devel Ther 9: 2399-2407, 2015.

32. Wang F, He L, Dai WQ, Xu YP, Wu D, Lin CL, Wu SM, Cheng P, Zhang Y, Shen M, et al: Salinomycin inhibits proliferation and induces apoptosis of human hepatocellular carcinoma cells in vitro and in vivo. PLoS One 7: e50638, 2012.

33. Qu H, Ma B, Yuan HF, Wang ZY, Guo SJ and Zhang J: Effect of salinomycin on metastasis and invasion of bladder cancer cell line T24. Asian Pac J Trop Med 8: 578-582, 2015. 